Reviews

\title{
Beswick, Jaine E. 2007. Regional Nationalism in Spain. Language Use and Ethnic Identity in Galicia. Clevedon, Buffalo, Toronto: Multilingual Matters Ltd.
}

Reviewed by Isabel Balteiro

University of Alicante

At first sight, some people might be surprised by the fact that a book devoted to Galician language and ethnicity is written in English. However, on second thoughts, if we stop to think for a while, this fact and its implications are, as we shall see, among the best achievements of this study. To begin with, the language used allows it to reach a broader audience since it may attract the attention not only of scholars and researchers interested in Galician and its issues but also any other person interested in sociolinguistics, language diversity, linguistic rights, ideologies and ethnicity, etc. In addition to this, it is quite important to underline that the author is a non-Galician writer, which consequently means that the work will most probably be impartial, neutral, rather than subjective and impassioned.

The book analyses, describes and explains linguistic, sociolinguistic, ethnic, cultural and socio-political aspects of Galician. Moreover, not only contemporary issues are dealt with but also historical matters such as the relationship between Galician and Spanish, on the one hand, and Galician and Portuguese, on the other. An interesting analysis of Galician revitalisation is offered, which is especially relevant if the pressure exerted by the Spanish language is considered. Also, the presence of two co-official languages, their use and role, and the speakers' perceptions are analysed. Despite the title of the book, which apparently excludes Portuguese, it deals quite extensively with the relation and similarities between Galician and this language, which makes sense for historical reasons but also due to the formal similarities that still exist between the two languages and related issues, such as self-identification practices, which are focused on on several occasions throughout the book.

The book is divided into three main parts, preceded by the foreword and an introduction and followed by some detailed notes on the chapters, seven appendices, a short glossary of linguistic (mainly phonetic) terms and the references.

Clive Willis, in the Foreword, introduces some of the main topics of the book: 1) the pressure exerted by the Spanish and Portuguese on Galician and the affinity of the latter with the former two; 2) the now fortunately completely disregarded and oldfashioned view that Galician is a dialect of Spanish; 3) the reluctance of the population in the cities to speak Galician. 
In the Introduction the author presents the framework of the book as well as some key concepts and anticipates some issues such as the users' attitudes towards Galician, diachronic and synchronic interaction, similarities and differences between Galician and both Portuguese and Spanish, the use of this language at different life stages, the question of whether a shift in language use is taking place, the relationship between nation and ethnicity, social and political linguistic policies and planning strategies, the question of whether Galician is an autonomous language, different from Portuguese, etc. The aims of this work as well as the four hypotheses that Beswick poses are also stated at this point.

Part I, "Politics and Privilege: Linguistic Identity and the Role of Standardisation in Galician," comprehends chapters one to three and is devoted to three basic notions in this work: language, culture and identity. Furthermore, it describes the use and status of Galician, and its origins from the time when it was Galician-Portuguese up to the present day. Chapter one outlines some of the main issues and concepts that are key for the rest of the book, such as nationalism and regionalism, ethnicity and multiple identities, the concept of multilingual community, linguistic and ethnic rights, political and social attitudes towards the language, revitalisation and revival, etc. Chapter two is one of the essential chapters, for it allows the audience to understand the contemporary state of Galician. It offers a political and historical approach to Galician from its origins and delves into issues such as the repression suffered by this language at different stages or periods in its "development". Probably its most relevant point is the consideration or appreciation of the changing status of Galician as a marker of ethnic identity from its former condition as Galician-Portuguese and later as a "dialect" of Spanish (resulting from territory divisions). Chapter three is linked to chapter two, both chronologically and thematically, as it focuses upon the contemporary Galician situation, which is mainly the consequence of the facts and situations explained in chapter two. Thus, the historical attempts to revitalise political, social and linguistic consciousness concerning the Galician language as well as democratic efforts to do so led to a need for an official Galician orthographic standard, that is, for the creation of a norm.

Part II, entitled "Forms and Features: Galician Linguistic Conventions and Characteristics", consists of chapters four to six and concentrates on matters such as diachronic development, similarities and differences between Galician and Portuguese, on the one hand, and Galician and Spanish, on the other; as well as idiosyncratic features of Galician, among others. Chapter four focuses on some basic concepts and issues for the discussion that follows. Thus, for example, the explanation of allophonic variation is of great importance for phenomena such as the gheada, which is explained in chapter six, or also that of code-switching. This concept, with all its linguistic and social implications, is taken up again in chapter nine. For these reasons, this chapter may be regarded as especially useful for readers who may be unfamiliar with linguistic concepts. Chapter five resumes some of the topics considered in chapters two and three, such as the diachronic evolution of Galician and the normativization or establishment of some Normas Ortográficas. But the main focus of this chapter is on the similarities 
between Galician and Portuguese and Galician and Castilian Spanish. Quite interestingly, the author concludes that there is a "transitional dialect" between Southern Galician and Northern Portuguese. Apart from that, she also examines the creation of an oral standard. Chapter six analyses (socio)linguistic variation by studying two prototypical phonetic or allophonic characteristics of Galician, namely, the gheada and the velar nasal, the former being (unfortunately) a common topic for pejorative jokes both outside and inside Galicia. According to Beswick, these two features may be considered as a mark of identity and also a basic concept for the arguments in favour of ethnicity in Galicia, as claimed in this book.

Part III is devoted to "Prestige and Practice: Language and Identity in Galicia" and comprehends chapters seven to nine. As explained in the following lines, in this part Beswick goes back to some topics commented on in the previous parts in order to emphasize revitalisation practices, bilingualism and diglossia in Galicia, etc. Thus, chapter seven is connected with parts two and three since it deals with questions such as sociolinguistic variation and normalisation in Galician. It also focuses on political, linguistic and educational issues which may be crucial for the survival of Galician. Moreover, the author examines the role of the media in language diffusion and people's attitudes towards it. Chapter eight analyses language use and selection and the domain of usage of Galician and Spanish by means of an empirical study carried out in Santiago de Compostela. For this purpose, the author interviews different age-group individuals, trying to determine whether language change (which seems to be in progress) and attitude towards the language are related to age. Chapter nine, the last one, summarizes the main arguments and discussions of the eight preceding chapters. Beswick concludes by arguing that the four hypotheses put forward at the beginning of the book have been corroborated. Though the stated resistance to eradicate the sense of Spanish identity is quite significant, the most original claim and/or conclusion of this work is, in our opinion, that there is an intrinsic character of Galician ethnic identity.

After this brief summary of the main topics and achievements of the book, the main impression one may have is that it is quite a complex work, due to its contents. However, after a careful reading of the study, the impression is different: it is a very readable tool in which all chapters are scrupulously related to each other as well as conveniently ordered. In general it may be said that the discussions can be easily followed thanks to, for example, the fact that the language used is not highly specialised. Thus, the book becomes one of the best sources for scholars but also for any person who may be interested in either the situation of Galician, even if unfamiliar with (socio)linguistics, or in sociolinguistics and/or minority languages in general. For specialised audiences it seems addressed in particular to those interested in topics such as minority languages, language identity, controversial issues concerning Galician, users' attitudes, normativisation and the similarities of Galician with Portuguese and Spanish, for example. Mention should be made of the treatment of Galician from its early stages until now, that is, the treatment of Galician diachronically and synchronically. The way in which controversial issues such as political and institutional 
matters are dealt with is also remarkable and illuminating. An in-depth study of all the already mentioned topics is carried out both theoretically and empirically.

In addition to the underlined advantages of the book as regards its readability and interest, structurally the work is also very attractive. Moreover, tables and figures throughout the book contribute to an appealing explanation and illustration of the different topics.

Perhaps one of the shortcomings of this book, if there is one, is that all the themes dealt with are commonplace for any educated person living in or closely linked to? Galicia. However, the book is a very good source of information for any person who is not familiar with the situation of Galician. Furthermore, a longitudinal study would contribute to corroborating some of the conclusions, instead of a chronological study of how people behave at different stages of their lives.

However, for all the above mentioned reasons, as well as for the onlooker approach adopted, the book is highly recommendable for any person interested in the Galician language. 
Reviews

Flys Junquera, Carmen and Maurice A. Lee eds. 2007. Family Reflections. The Contemporary American Family in the Arts. Alcalá de Henares: Servicio de Publicaciones de la UA. 340 pp.

Reviewed by María Teresa González Minguez

Manuel E. Patarroyo High School

Recent decades have seen the publication of a range of works such as Elaine Tyler May's Homeward Bound: American Families in the Cold War Era (1988), Ella Taylor's Prime-Time Families: Television Culture in Postwar America (1989), or Stephanie Coontz's American Families: A Multicultural Reader (1998) and The Way We never Were: American Families and the Nostalgia Trap (2000) which delve into family itself or its representation in the arts. However, responding to a need for an innovative view of the family, a rather unique position is now taken by Carmen Flys Junquera and Maurice A. Lee who have thoughtfully approached this relevant theme from other perspectives: how the contemporary American family represented in the arts acts as a focal point in our global culture as regards the large amount of social observation one can obtain from popular genres such as television, cinema, theatre and literature.

Flys and Lee, who have brought together an impressive team of scholars from both sides of the Atlantic, question how the arts portray the family, why the media choose to draw the images that it does of the American family and if this portrayal is a reflection or a distortion of reality. Many of the articles included were based on a seminar held at the Research Institute for American Studies of the University of Alcalá where the American family was the central theme. From this seminar, the initial presentations were redefined and focused, and additional contributions, such as examples of creative writing, were solicited.

In their Introduction the editors start by making the audience aware that America is now the most culturally diverse country in the world and one that is likewise constantly changing through even more diverse cultures immigrating to it. Nevertheless, despite the many ethnic groups living in the country, the general role the family plays is to provide one with a sense of growth and morality. The values of success, good health, hard work, and education are closely aligned with the concept of family. The difficulties, the nightmares, the disappointments, and the tragedies are no obstacle for the average American family who truly believes that the American dream is attainable, if one works hard. Flys and Lee state that the true image of the typical American family is, on occasions, seldom seen in the arts and the media because many portrayals in search of an audience simply focus on deviations. Thus, their main intention is "to 
provide a background on which a comparison can be made between what is represented and what is fact" (16). For this reason, they have chosen to divide the book into three general sections: Visual Arts, Creative Arts and Narrative Arts. In the first they have included critical papers dealing with film and television which offer interesting interpretations of classic series and movies. The second groups short stories, poems and personal essays offered by American writers. Some are extremely personal reflections and others more distanced. In the final section, the longest, they have placed the critical articles on literary representations in literature, particularly ethnic families in the United States. In reviewing Flys and Lee's book below, I follow this threefold structure and seek to highlight the study's numerous strengths.

\section{a) Visual Arts}

This section opens with Manuela Ruiz Pardos's contribution focused on Billy Wilder's popular film The Seven Year Itch (1955) in which she explores some of the tensions surrounding the postwar representations of family ideals in the genre of comedy. The postwar American family is described as vulnerable and enslaving but it is eventually reshaped as a protecting shelter that American husbands should invariably treasure. However, far from being the unproblematic, desirable frame for masculinity, the family seems to emerge as a fluctuating sphere characterized, Ruiz points out, by "instability and contradiction rather than by consistency and certainty" (Flys and Lee, 2007: 36).

Although centred in the postwar era and the 1970s, Pilar Rodríguez Berruete shows the debate about the contemporary nuclear family. Analysing The Sound of Music and Star Wars Rodríguez Berruete explains that the family is under threat by means of a metaphor: both films were released as "blockbusters" to compete for televison audiences and this shows the danger that cinema suffered as a consequence of the increasing power of television after the 1950s. The change of roles presents Captain von Trapp, the father in The Sound of Music, not as a strict and authoritarian figure any more but as one who tries to approach his children showing a tender figure: "to be better fathers, men have to be more like women” (Flys and Lee, 2007: 52). In Star Wars Princess Leia, the central female character, is more heroic as a result of the 1960s feminist liberation movements. As Rodríguez Berruete puts it, the figure of the absent parent appears in both films and lone parents deal with their children (Flys and Lee, 2007: 40). They do not mind making a fool of themselves to see their children happy and are quite successful, a fact that calls the inevitability of the nuclear family into question.

Comparing Maya Angelou's film Down in the Delta (1999) with the direction of Orson Welles' The Magnificent Ambersons (1943) and Francis Ford Coppola's The Godfather, Part One (1970), Wayne Stengel describes the American family as a masculine system of rules, codes, and strategies. Nevertheless, Stengel proves, that Angelou offers an alternative view presenting the American family as a shaping instrument of feminine love, strength, and resilience and not merely as the site where men impose standards of control, order, and authority. 
Carmen Valero Garcés bases her discussion on Poyato's model of culturemes to analyse four films, The Story of Us (1999), American Beauty (1999), My Family (1995), and The Perez Family (1955) and the different cultural values represented in each. She so rightly notes that unlike the Anglo-Americans, who see the family as a small, personal, and affectionate unit, the Latinos' image of the family conveys a large social institution which usually involves an extended network of role-relationships with little emphasis on personal choice and affective ties.

In an essay with wide-ranging examples Janet $\mathrm{K}$. Wilson examines the extent to which popular family-based television programmes in contemporary America actually reflect the American family structure as reported by the US Census Bureau. Reviewing series from the 1950s to the 1990s such as I Love Lucy, The Beverly Hillbillies, Good Times, Murphy Brown or Frasier which show nuclear families, rural comedies infiltrated with traditional ethics, professional families with both working parents, single mothers, homosexual characters and intergenerational households, she concludes that "family-based programming decisions are made to create a domestic dynamic that is 'consumed' by the largest portion of American audience” (Flys and Lee, 2007: 89).

Two prime-time sitcoms of the 1980s and 1990s are scrutinized by Diederick Oostdijk in the last article of this section. The Cosby Show and The Simpsons portray family life in such radically different ways and reveal a great deal about the changes in American society during these two decades. The Huxtables in The Cosby Show are the epitome of the successful nuclear family. In contrast, The Simpsons show a disintegrated and clueless family which almost seems a parody of the idealized Huxtables. Criticising The Cosby Show for its lack of political motivation, Oostdijk perceives that the waning interest in this sitcom combined with the immense popularity of The Simpsons suggests an altered mood in American society with other political and social occurrences at the time such as the Los Angeles riots and Clinton's election.

\section{b) Creative Arts}

Maurice Lee begins the second part of the volume with "Payday," a short story about his own admiration as a child for his father. A black man who never boasts about himself shows his child that talent and respect for family values are the ingredients which lead to success.

"Queretaro," "Family of Two," and "Susana Escamilla," three poems by María Herrera-Sobek, express the Mexican experience of family in ballad and song with a curious use of code-switching. Indians, grandparents, and large families narrate their experiences in "the land/of no return" which is, at the same time, "the land of milk and honey” (Flys and Lee, 2007: 119).

The dramatic loss of traditional Indian heritage is the central topic of Diane Glancy's “Father," a moving essay which recounts the conflicting feelings of a girl for her father, a man that lived a moral life and was romanticized by a daughter who tried to see him in every man she met. 
Velma Pollard's bright images invade her poems. "Bitterland" is a tribute to Caribbean immigrants from one of their own. Sharp onomatopoeic lines like "The scars like keloids" impress the reader who perceives that people's new roots only grow in air in Brooklyn and the Bronx.

East meets west in "Distances," a story in which Vijay Lakshmi portrays the difficult adaptation of an Indian woman to the American life style. While her family accepts America and the dreams it offers, the woman finds herself still clinging to the past. Her husband and children -the bridge between the two cultures- hold her responsible for her own misery for she remains immobile, remembering the fragrances of her homeland.

In the next narrative, "The Moment," Katie Singer reflects on her feelings for a distanced and not very affectionate father during a visit to the family home. Although he was married for the third time, the protagonist feels a need to protect him as if trying to supplant his wife and save his emotions.

Finally Wayne Stengel bases his essay on films of different eras -The Night of the Hunter (1955), The Shining (1980), and American Beauty (1999)- to depict an increasingly decadent father. The sacred Hollywood figure of the fifties suddenly becomes a "questionable moral authority" (Flys and Lee, 2007: 143) in a monolithic society that was starting to collapse because the head of the household is less connected with the family he cares for.

\section{c) Narrative Arts}

In the first article of this section Begoña Simal González undertakes a detailed analysis of sisters and doppelgängers in Amy Tang's The Hundred Secret Senses (1995). The book explores one of the most bitter necessities for Asian Americans, that is, having to be content with the total devaluation of their Asian ethnicity to become acceptable to a racist society. When Chinese Kwan dies, she literally redeems her American sister Olivia who will never understand life as she did before because now she knows of the existence of an important cultural and ethnic factor that the Asian American community seems to have forgotten about.

Following the theme of Asian American literature, Rocío García Davis focuses on the mother-daughter relationship through the absence of the mother on both personal and cultural levels. Ahn Joo and Ivah, the protagonists of Patti Kim's A Cab Called Reliable (1997) and Lois-Ann Yananaka's Blu's Hanging (1997) engage maternal loss as part of a process that highlights uncertainty and insecurity in the context of evolving American civilization since the mother means "the traditional source and sustenance in multicultural America” (Flys and Lee, 2007: 176).

In what may probably have been her last article, Cristina Blanco Outón also addresses the issue of the Asian family by finding parallels and differences between two characters: the 30-year-old Chinese protagonist of Amy Tang's “A Pair of Tickets" (1995) and the young Indian wife of Bharati Mukerjee's “A Wife's Story” (1995). The two figures incarnate a variety of family divisions between their ancestral minority and 
the modern American culture. However, as Blanco Outón extensively proves, each of them embodies a different approach to the same conflict: how to confront family values and traditions when the post-colonial era forces them into diaspora.

Analysing books such as House Made of Dawn (1968) by N. Scott Momady or her own Pushing the Bear (1998), Diane Glancy emphasizes the importance of ancestors and the sense of loss that affects the Native American culture now devastated by alcohol, poverty and purposelessness. Glancy recognizes that the oncoming Europeans have almost destroyed a vital background that the American Indian family is trying to rebuild. Also concerning American Indian families Aitor Ibarrola Armendariz reviews Louise Erdrich's Love Medicine (1984) and Leslie Marmon Silko's Storyteller (1981), two fictional works packed with images that suggest that the broken families portrayed there will only be restored by a return to nature that the Euro-American civilization has destroyed.

Taking into account the derogatory Moynihan Report, the purpose of María Frías Rudolphi is to review the portrayal of some single black mothers in the works of Veronica Chambers, Gloria Naynor, Ann Petry and Connie Porter as far as Langston Hughes' poem Mother to Son which confirms that, despite difficulties, single black mothers have traditionally resisted and challenged those statistical assumptions. "Life for them," Frias concludes, "has not been a crystal stair” (Flys and Lee, 2007: 248) but despite the never-ending struggle, these mothers keep climbing up.

The Afro-Caribbean family studied by Ana María Fraile in Elizabeth Nuñez' novel Beyond the Limbo Silence (1998) presents this community as the main source of social and cultural support and as a stifling context which the protagonist needs to escape. From a global diachronic perspective Fraile views the reconciliation of the Amerindian, European, African, and Asian heritage which shapes the Caribbean identity as a metaphor for colonial identity.

Rather than focus on an ethnic group, Carmen Flys Junquera focuses on the detective novel written by such authors as Walter Mosley, Barbara Neely, Louis Owens or Lucha Corpi and analyses how some ethnic detectives alter the dominant cultural values inherent in their communities. She examines the strong family values of both African American and Native American detectives and points out the minimal presence of family ties in Latino detectives, contrary to what is traditionally expected of Chicanos. With their creativity these writers symbolize the cultural values of mainstream America and present alternatives which make their literature appear, in Flys' words, “as part of an emancipatory cultural expression for their respective communities” (Flys and Lee, 2007: 288).

Rute Beirante notes how television mediates families' self-image and behaviour and clearly embodies the way families are presented and represented in Bobbie Ann Mason's Shiloh and Other Stories (1982). She underlines how its characters associate their cultural atmosphere with the television environment making its viewing "a fundamental form of organization in America” (Marc, 1995: 142).

The two last chapters in this book are devoted to Latino families. Concepción Bados Ciria presents the only chapter on theatre placing emphasis on plays written by Chicana 
authors such as Josefina López's Simply Maria (1992). If Chicano authors encourage the family's unity in a passive way, in the plays written by Chicanas, Bados singles out how women transform their silence into speech and succeed in undermining patriarchal society to create a space for themselves. María Herrera-Sobek seems to be conscious of the fact that the centre of the universe in Latino culture is the family but after examining four novels by Lucha Corpi -Eulogy for a Brown Angel (1992), Cactus Blood (1995), Black Widow's Wardrobe (1999) and Crimson Moon (2004)- she finds other models of family relationships, particularly those which do not adhere to traditional models of being and behaving. Her article contrasts and complements that of Carmen Flys Junquera as she provides us with various possibilities of family interactions extant in the complex world we inhabit nowadays.

Arts show the effects of the cultural, economic and social changes that operate in American society. Those changes do have a clear influence on the representation of the family. After the 1920s, the family became a central social unit and the primacy of the individual was threatened. Then in the 1950s and early 1960s it was partly disintegrated because of the sexual revolution and the collapse of well-defined roles ${ }^{1}$. Up to the 1960s society was more concerned with mothers showing a repressive and authoritarian father-like figure. The crisis of the nuclear family was later revitalised in the late 1970s and the beginning of the 1980s, where there appear problematic omnipotent fathers. In the 1990s the Americans were ready for a change and demythologized marriage as an everlasting love bond and new types of families (single parent, homosexual) were not viewed as bizarre. However, despite its vulnerability, the American family is still the basis for the foundation of individual and social identities and contributes to forming a web of connections, solidarities and ideas that truly cross boundaries. Its representation in literature, cinema and television is either a mirror of the social situation or a model to imitate.

Family Reflections is an analytically innovative work which combines literary strategies and social aims. The book responds to a need for a collective and multifarious review of the family unit in the last century. The editors' objective has clearly been to provide the reader with as much information as possible, which they have indeed fulfilled staying true to their commitment to link several disciplines. Thanks to the documentary efforts of the contributors to this appealing collection of essays and narratives it is possible to bring about an almost complete understanding of the American family. All the sections present illuminating and valuable pieces of scholarship that include a high number of bibliographical references. It is doubtlessly an example of sound, well-informed and well-written academic work that consolidates and exceeds the achievements of decades of criticism. One does not lack for reasons to celebrate the arrival of this new volume. 


\section{Notes}

1. Stephanie Coontz notes that the crisis of family life may respond to the equality of the sexes. In those societies in which men and women have similar opportunities, the birth rate will decrease (2006:18).

\section{References}

Coontz, Stephanie. (1998): American Families: A Multicultural Reader. London: Routledge. .(2000): The Way We never Were: American Families and the Nostalgia Trap. New York: Basic Books. .(2006): Historia del matrimonio. Barcelona: Gedisa.

Marc, David. (1995). Bonfire of the Humanities. Television, Subliteracy and Long-Term Memory Loss. Syracuse: Syracuse University Press.

May, Elaine Tyler. (1988): Homeward Bound: American Families in the Cold War Era. New York: Basic Books.

Taylor, Ella. (1989): Prime-time Families: Television Culture in Postwar America. Berkeley: The University of California Press. 